\title{
Science and Social Problems
}

\begin{abstract}
WHE first meeting in London of the British Association's new Division for the Social and International Relations of Science was held in the Royal Institution on May 25. Sir Richard Gregory presided and in his introductory remarks sketched the genesis and adumbrated the programme of the new movement. Co-operative work in the special sciences was carried out for sixteen years by the International Association of Academies, and then by the International Council of Scientific Unions, which was formed during the Great War and is still active. Two years ago, on the initiative of the Royal Academy of Amsterdam, an entirely new outlook was adopted by including within the scope of the Council the social significance of the applications of science, thus endorsing the conviction of many that scientific workers can no longer remain indifferent to the social consequences of their discoveries. No definite programme of work has yet been formulated, but the essential idea is to apply the scientific method of inquiry to problems arising from the interactions of natural science and society. The British Association, acting in co-operation with its sister association in America, and through its new Division, is well adapted to promote such inquiries, and with this object in view it is arranging to hold meetings not only at the time of the annual meeting of the Association but also at other times and places as occasion may arise.
\end{abstract}

Dr. Ernest Barker, professor of political science in the University of Cambridge, then gave an address on "The Impacts of Science on Society". Natural science acts on society in two main ways : first, by developing a special science, or a body of social sciences, explaining society as a natural phenomenon, and thereby helping it to control itself consciously; and secondly, by producing discoveries and inventions which indirectly affect social behaviour and the general structure and functioning of society. The first way is mainly that of the biological sciences. To-day we do not see society as an engineering contrivance based solely upon matter and motion, but as something organic and vital, which evolves, and whose parts are permeated with interflowing dependence. This view has not only profoundly influenced the study of history, the study of law, and the criticism and understanding of art, but also it has altered our outlook on society itself. A society that interprets itself in biological terms behaves differently in virtue of that new interpretation; the difference may work for evil as well as for good-for example, in the direction of a perverted nationalism, -but the application of general biology to human society is not condernned by the possibility, or the fact, of misapplications.

The second way of action is one both of physical and chemical science and of biology. Physics and chemistry have revolutionized the methods and pace of communication, both material and mental ; they have revolutionized industrial production and the art of war. The changes thus brought about are greater than the changes due to political causes. Should science attempt to control the changes which it causes? In Prof. Barker's view, science must proceed with the single regard of discovering truth; if progress were stopped, an evil might be averted but a greater good might be missed; the utmost concession is a slowing down of the impact. It is the business of society, through its leaders, to control the effects, and the one duty of the man of science is to contribute the resources of his own training and technique to the making of a proper and exact estimate of the nature of the changes and of the nature of the relevant remedies.

Biology differs from physics and chemistry in its influence on society, in that its discoveries can be applied most directly, most intentionally and most fruitfully, through the soil and through plants and animals, to the relief of man's estate. The discoveries of genetics and eugenics can improve the strains of plants and animals and the human breed itself. But the improvements arrive very slowly owing to the impedimenta offered by human nature : "sentiments that teem with embarrassing anachronisms, of which we are usually unconscious", embedded habits, traditions, instincts and emotions. Therefore the conscious application of science to the improvement of life will always be a slow-motion picture; the delay, however, may enable science to become sure of its discoveries before they are applied, and thus produce a greater security both of scientific and of human progress.

Sir Daniel Hall, unlike the previous speaker, discussed a concrete theme: "How the application of science to agriculture is impeded". It is necessary, he said, to distinguish between peasant farming, which is virtually self-contained and independent of world markets, and agriculture regarded as an industry, which can look to science for increasing, improving and cheapening its production. There is much peasant farming still in England, where 61 per cent of holdings belong to the $1-50$ acre class, and upon which there is relatively little scope for scientific improvements. On farms of all types and sizes there is an average of one master to four or five workers, so that even the larger units of production are very small compared with the units of great urban industries. This fact, together with its consequences, lack of prospects for educated youths without capital, discontinuity of effort, and lack of capital, restricts the application of scientific developments. The importance of time-lag between preparation and production is sometimes exaggerated, but the handicap may be very serious when falling prices intervene. A greater handicap is that of variable weather, which may necessitate waiting for five years or more before the costs of production of a crop can be determined.

The adoption of inventions in machinery is limited by the small size of the farming units; the use of combine harvesters and crop driers is out of the question on most English farms. Equally impracticable are many large works of land improvement and organization, which affect areas beyond the ownership of a single proprietor, but which science indicates would be practicable on a large scale and a long view. The retail structure of agriculture also precludes the exploration of scientific discoveries and inventions, because there are no great agricultural producers to act as intermediaries in translating a laboratory into a large-scale process. 
Basic research is outside the farmer's scope, but he can put into practice some of the findings of research organizations; for example, those relating to the effects of fertilizers, improved yields of new varieties or stock, and disease treatment. State intervention is needed in many fields to secure the prosecution of research for the benefit of agriculture, and to make known its results. If increased and cheapened production is regarded as a necessity in the modern State, intervention of another kind is needed to free agriculture from some of the limitations imposed by its present structure; failing that, there is danger that the factory will replace the farm in the production of essential commodities.

The meeting was very well attended, and at the close Prof. A. Ferguson referred to possible research work that might be undertaken by the Division, such as a study of the development of nationalistic feeling, and the history of Westerm thought. Such interesting and important studies would be welcomed by many, but it may be suggested that they should not take precedence over the essential task of attacking concrete problems in a scientific way. Sir Daniel Hall's remarks on the necessity for State intervention in agriculture suggest that a suitable study would be the very old, but still very important, question of land tenure, of public control of the land and its utilization. Such a study, it might be objected, would inevitably lead to 'impact', that is, collision, with politics, but it need not be treated in a politicocontroversial way. What is needed are the reasoned judgments of trained scientific workers, who have no economic, political, social or other axes to grind, who are capable of submerging the embedded sentiments, of which Prof. Barker spoke (except that of justice), and above all, who will take the vow of placing the common good above all the lesser loyalties, like political party, social class, and the 'old school tie'.

E. H. T.

\section{Hydrogenation}

D URING May 24-26, a conference was held in Paris under the auspices of the five chemical societies which share the amenities of the Maison de la Chimie there. The selected subject was the various aspects of hydrogenation. This is the second occasion on which the same five societies have co-operated. An average attendance of more than three hundred was attracted. The meetings commenced at 4.30 in the afternoon, so enabling the participants to go about their ordinary affairs during the working day. The chief figure at the meeting was Prof. Sabatier of Toulouse, still hale and hearty at eighty-four years of age : his original researches are recognized as having given the first impetus to the study of all subsequent hydrogenation reactions, some of which are technically in the forefront of world interest to-day. The presidents of four of the societies presided in turn over the sittings.

The conference appropriately began with a paper from Sabatier, largely of an historical nature, relating to the addition of hydrogen to unsaturated compounds in presence of nickel. Prof. Paul followed with an account of the Raney nickel catalyst. The evening discourse delivered by Prof. Aubel, of Paris, dealt with the general phenomenon of hydrogenation in biology. On the next afternoon, Prof. N. V. Ipatieff, who now holds a chair at the Northwestern University of Chicago, spoke on the use and advantages of copper and copper chromium catalysts for the hydrogenation of benzene and its derivatives, describing work which is being followed with considerable interest. The following paper was delivered by Dr. E. F. Armstrong, who dealt fully with the technical and industrial development of hydrogenation, first in regard to fat hardening, which has now largely become standard practice; afterwards he indicated the methods of manufacture of hydrogen and the approximate cost of this gas, describing also the line of attack which is being followed in the conversion of water gas into petroleum hydrocarbons, and of coal, under pressure, into methane.

At the conclusion of the meeting, Messrs. Ipatieff and Armstrong were each presented with a Chevreul Medal in recognition of their labours in their respective fields of inquiry. The meeting ended with a banquet held in one of the large lecture rooms of the Maison de la Chimie, which readily lent itself to this conversion and was provided with the necessary auxiliary accommodation behind the scenes. The excellent facilities provided here for our French colleagues are the cause of renewed admiration and envy on every occasion we avail ourselves of them. They enabled a first-class banquet with wines to be staged for the modest charge of 60 francs.

The third day was primarily concerned with the official celebration of the twenty-fifth birthday of the Société de Chimie Biologique, but even here the role of active hydrogen was not overlooked, being made the subject of a paper by Prof. Thunberg of Lund.

\section{Work of the Cornish Engineers}

N the form of a reprint from the Journal of the
Royal Institution of Cornwall, there has been
published at the Royal Printeries, Truro, a paper
by W. Tregoning Hooper entitled "The World's Debt
to Cornish Engineers", one of the aims of which is
to commemorate the historic experimental trials of
the Austen's 80 in. Cornish pumping engine. At these
trials, this engine established a record of accomplish- ment which demonstrated to men of science, engineers and economists the great potentialities of the power of steam, and the occasion is, therefore, a fitting one to be recalled and celebrated.

In the year 1835, in collaboration with his chief engineer, West, Joseph Thomas Treffry erected a new 80 in. engine and it was stated to have done a duty of nearly 98 million foot-pounds of work per 